\title{
Hidrogeno-ekoizpena bio-oilaren erreformatze katalitikoaren bidez
}

\author{
(Hydrogen production from catalytic reforming of bio-oil) \\ Aingeru Remiro ${ }^{1 *}$, Lide Oar-Arteta ${ }^{2}$, Ana G. Gayubo ${ }^{1}$ \\ ${ }^{1}$ Ingeniaritza Kimikoa Saila, Zientzia eta Teknologia Fakultatea (UPV/EHU) \\ ${ }^{2}$ Catalysis Engineering / ChemE / TUDelft (The Netherlands) \\ * aingeru.remiro@ehu.eus
}

DOI: $10.1387 /$ ekaia.17272

Laburpena: $\mathrm{H}_{2}$-aren eskariaren igoerak, petrokimikako lehengai eta erregai garbi gisa erabiltzeko, petrolioaz bestelako lehengaiak jatorri duten prozesuen garapena bultzatu du. Prozesu horien artean, biomasak arreta berezia bereganatu du haren erabilgarritasunagatik eta berriztagarritasunagatik. Biomasatik $\mathrm{H}_{2}$-a lortzeko zeharkako bideek gero eta jakin-min handiagoa eragin dute, esate baterako, biomasatik eratorritako oxigenatuen bidezko lurrun erreformatzeak. Horien artean, bio-oilak interes handia dauka, beste bideek baino bideragarritasun ekonomiko handiagoa izan baitezake. Izan ere, bio-oilak ekoizpen deslokalizatua izan dezake biomasaren ekoizpen-fokoetan eta ondoren, unitate zentralizatuetara garraia daiteke balioztatzeko. Dena dela, prozesu horretan kontuan hartu beharra dago lignina pirolitikoak sortzen dituen arazoak, zehatzago, erreakzio-ekipoan eta katalizatzailean depositatzen den hondakin solidoa bio-oila lurruntzen denean. Arazo hori gainditzeko, beharrezkoa da teknologia eskalagarria. Horretaz gain, katalizatzaile aktibo, selektibo eta iraunkorren garapena funtsezkoa da prozesu horren bideragarritasuna lortzeko. Lan honetan, bibliografian dauden bio-oilaren erreformatzearen estrategia nagusiak aurkezten dira, ikerketa-taldearen emaitza originalak nabarmenduz.

Hitz gakoak: bio-oila, hidrogeno ekoizpena, lurrun erreformatzea, $\mathrm{CO}_{2}$-aren harrapaketa, ohantze fluidizatua.

Abstract: The growing demand of $\mathrm{H}_{2}$ for its use as petrochemical raw material and
clean fuel has boosted the development of processes for its production from alternative
sources to oil, among which biomass has received special attention due to its availabil-
ity and renewable nature. There is an increasing interest in the development of indirect
routes for $\mathrm{H}_{2}$ production from biomass, via steam reforming of biomass-derived oxy-
genated compounds. Indirect pathways to obtain hydrogen from biomass, such as the 
steam reforming of oxygenates derived from biomass, are these days in the spotlight. Among them, the so called bio-oil deserves special attention, due to its economic viability. Actually, delocalized production of bio-oil in biomass production plants allows for its subsequent transportation to centralized units for its further valorization. However, problems caused by the pyrolytic lignin produced during this process need to be also considered, specially, the solid residue deposited on both the catalyst and the reaction setup when bio-oil evaporates. Scale up technology is deemed necessary in order to solve this drawback. Moreover, the development of an active, selective and stable catalyst is of the utmost importance towards achieving full viability of the process. In this piece of work, we aim at giving an overview on the main bio-oil reforming strategies in literature, with special emphasis on the results from our research group.

Keywords: Bio-oil; Hydrogen production; Steam reforming, $\mathrm{CO}_{2}$ capture, Fluidized bed.

\section{SARRERA}

Energia eskariaren igoerak petrolio gordinaren gehiegizko ustiapena ekarri du, garatuta dauden herrialdeetan ongizatea mantentzeko, eta ongizate hori lortzeko Asian eta Hegoamerikan garatzen ari diren herrialdeetan. Petrolioaren ustiatze ugaria duela mende bat hasi bazen ere, paradigma-aldaketaren aurrean gaude, bi arrazoi nagusik bultzatuta; i) agortzearekin lotutako petrolio gordinaren apurkako garestitzea, arrazoi geopolitikoek eta espekulatiboek sortutako prezioen gorabeherak alde batera utzita, eta ii) klima-aldaketaren aurkako borrokak eragindako gizarte-kontzientzia handiagoa eta erregai fosilen ageriko ondorio kaltegarriak [1]. Bi alderdi horiek baldintzatzen dute hurrengo hamarkadetan gauzatu beharreko energia-trantzisioa, betiere bideragarritasun ekonomikoari lotuta eta ingurumen-inpaktutik eratorritako gizarte presioak baldintzatuta. Agertoki honetan hidrogenoaren erabilera bestelako energia-eramaile iraunkor gisa azaleratzen da, ura edo biomasa moduko lehengai berriztagarrietatik lortzen denean.

Hidrogenoa ekoizteko metodoak askotarikoak dira eta lehengaiaren arabera sailka daitezke: i) iturri fosilen erreformatzea, ii) jatorria biomasan duten bideak eta iii) uraren bereizketa elektrokimikoa [2]. Egun, orotara 500 bilioi $\mathrm{Nm}^{3} \mathrm{H}_{2}$ ekoizten dira, \% 96 erregai fosiletatik eta \% 48 gas naturalaren erreformatzearen bitartez [3]. Hala ere, epe labur-ertainean biomasa lignozelulosikotik eratorritako $\mathrm{H}_{2}$-aren ekoizpenak (elikadura-katetik aldenduta) interes ukaezina du, $\mathrm{CO}_{2}$-aren isurketa murriztuengatik, baliabide unibertsala delako eta ekarpen handia egiten diolako ekonomia sozialari eta iraunkorrari [4].

Bi multzotan sailka daitezke biomasa jatorria duten $\mathrm{H}_{2}$-aren ekoizpenaren bideak: i) ekoizpen zuzena (gasifikazioa, tenperatura altuko pirolisia, pirolisi katalitikoa eta prozesu biologikoak) eta ii) zeharkako ekoizpena, 
tarteko etapetan konposatu oxigenatuak lortuz (etanola, metanola, bio-oila, etab.) eta ondoren, erreformatzea eginez [5]. Bigarren bidearen garapen teknologikoak arreta handia erakarri du bibliografian. Horren arrazoiak dira dentsitate energetiko altua eta konposatu oxigenatu horien ziurtasun erlatiboa garraioari eta biltegiratzeari begira. Gainera, biomasaren balioztatze zuzenarekin alderatuta, bio-oilaren erreformatzean, bio-oilak dentsitate energetiko handiagoa du, eta horrela biltegiratze- eta garraio-gastuak txikiagoak dira [6]. $\mathrm{H}_{2}$-a ekoizteko biomasaren balioztatze-bideak 1. irudian erakusten dira, nabarmendurik bio-oilaren erreformatze-bidea.

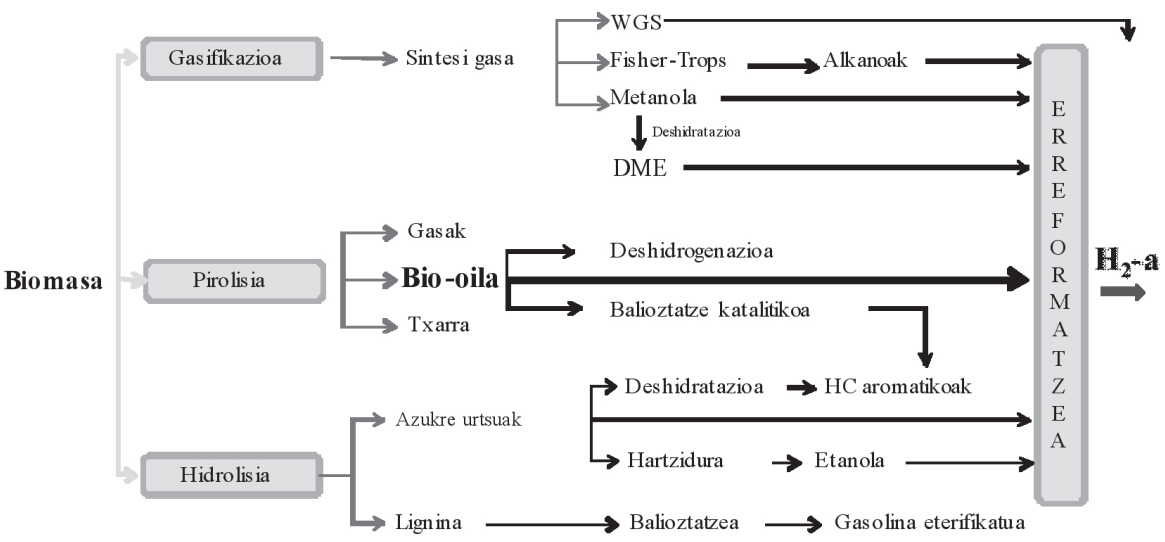

1. irudia. Hidrogenoaren ekoizpena tarteko konposatu oxigenatuen erreformatzearen bidez [7].

Bio-oila erreformatzea da, etorkizunera begira, biomasatik $\mathrm{H}_{2}$-a lortzeko bide oparoenetariko bat. Bio-oilaren balioztatzearen onura deslokalizazio-zentralizazio estrategia batean oinarrituta dago, hau da, pirolisiinstalazio ugari kokatzea biomasa-baliabideetatik geografikoki hurbil eta, produktu likidoa (bio-oila) garraiatu ondoren, haren balioztatzea zentralizatua eta eskala handikoa izatea. Izan ere, pirolisi-instalazioek teknologia erraza, ingurumen-inpaktu txikia eta koste baxua dute [8].

Bio-oila da biomasa lignozelulosikoaren pirolisi azkarraren produktu likidoa [9]. Likido marroia, polarra eta hidrofilikoa da, zelulosa, hemizelulosa eta ligninaren despolimerizazioaren eta zatiketaren produktuez osaturik dago. Tarteko produktu horien bereizte eta hozte azkarrak, eta haien erreaktibotasunak ezegonkortasuna eragiten dio bio-oilari.

Bio-oila da konposatu oxigenatuen eta uraren nahastea, eta haren konposizioa hasierako biomasaren eta pirolisi baldintzen araberakoa da. GCMSren bitartez, 300 konposatutik gora identifikatu dira [10] eta horiek hainbat familiatan sailka daitezke: zetonak, azido karboxilikoak, aldehidoak, alkoholak, eterrak, esterrak eta konposatu fenolikoak [11]. 
Bio-oilaren lurrun bidezko erreformatzearen (hemendik aurrera $l u$ rrun erreformatzea) erreakzio nagusiak dira oxigenatuen erreformatzea (1. ekuazioa) eta water gas shift (WGS) erreakzioa (2. ekuazioa), seriean:

Oxigenatuen erreformatzea:

$$
\mathrm{C}_{\mathrm{n}} \mathrm{H}_{\mathrm{m}} \mathrm{O}_{\mathrm{k}}+(\mathrm{n}-\mathrm{k}) \mathrm{H}_{2} \mathrm{O} \leftrightarrow \mathrm{nCO}+(\mathrm{n}+\mathrm{m} / 2-\mathrm{k}) \mathrm{H}_{2}
$$

WGS erreakzioa:

$$
\mathrm{CO}+\mathrm{H}_{2} \mathrm{O} \leftrightarrow \mathrm{CO}_{2}+\mathrm{H}_{2}
$$

erreformatzearen erreakzio orokorra gertatuz:

$$
\mathrm{C}_{\mathrm{n}} \mathrm{H}_{\mathrm{m}} \mathrm{O}_{\mathrm{k}}+(2 \mathrm{n}-\mathrm{k}) \mathrm{H}_{2} \mathrm{O} \leftrightarrow \mathrm{nCO}_{2}+(2 \mathrm{n}+\mathrm{m} / 2-\mathrm{k}) \mathrm{H}_{2}
$$

Erreformatze-prozesua 3 bide nagusitatik egin daiteke $\mathrm{O}_{2}$-a elikatzeko moduaren arabera [12]:

Lurrun-erreformatzea (steam reforming, SR), ur-lurrunaren korrontea elikatuz. Oso prozesu endotermikoa da, baina horrekin $\mathrm{H}_{2}$-aren etekinik altuena lortzen da;

i) oxidazio partziala (partial oxidation, PO), oxigenoa elikatuz. Prozesu exotermikoa da eta erreformatzearen behar energetikoak murrizten ditu, baina $\mathrm{H}_{2}$-aren etekina txikitzen da, eta

ii) erreformatze oxidatiboa (oxidative steam reforming, OSR) eta autotermikoa (autothermal reforming, ATR). Azken hori SRaren eta POaren arteko nahastea da, non $\mathrm{O}_{2}$-a eta ur-lurruna elikatzen diren. Bide honetan, egoera autotermikoa lor daiteke $\mathrm{H}_{2}$-aren etekinean murrizketa handirik eragin gabe.

iii) Bestalde, bio-oilaren erreformatzearen arazorik garrantzitsuena da ligninaren pirolisia jatorri duten konposatuek birpolimerazio-arazoak sortzen dituztela. Hain zuzen ere, bio-oila lurruntzeko berotzen denean, konposatu horiek solido bihurtzen dira eta elikatze- zein operatibitate-arazoak sortzen dituzte, erreformatzearen katalizatzailearen desaktibazioa areagotzeaz batera [4]. Burbuilazko ohantze fluidizatuaren eta zirkulazio-ohantzearen erabilerek ekiditen dituzte kokez (metatutako solido karbonotsua) gaineztatutako partikulak eta ohantzearen blokeoa (ohantze finkoan eta ohantze mugikorrean halabeharrez blokeatzen da ohantzea).

Arazo horiei irtenbidea emateko hainbat estrategia proposatu da, aurretratamendu edo diluziorik gabeko bio-oilaren (hots, bio-oil osoaren) balioztatzea lortze aldera. Hala eta guztiz ere, konponbide zuzena eta eskalagarria lortzeke dagoen erronka da. Horregatik, gaur arte katalizatzaileen alderaketa eta 
bio-oilaren erreaktibitateari buruzko ikerketa-lan gehienak egin dira bio-oila osatzen duten konposatu ereduekin. Haien artean, azido azetikoa da ikertuena, Ni katalizatzaileak erabiliz (La eta Co sustatzaile moduan erabiliz) [13-15]. Katalizatzaile mota horrekin beste hainbat konposatu ereduren erreformatzea ikertu da, hala nola, azetonarena eta fenolarena [16], azetolarena (hidroxiazetona) [17], toluenoarena (tar-a simulatuz) [18, 19], m-kresolarena, dibenzileterrena, glukosarena, xilosarena eta zukrosarena (tar-a simulatuz) [20].

Lehenengo aro batean, bio-oilaren tratamenduaren aurrerapenak frakzio urtsuaren eskutik etorri dira, konposatu polimerizagarrien kopurua biooil osoan baino askoz txikiagoa delako eta, horrela, oztopo gutxiago sortzen dituelako bio-oil osoaren erreformatzean baino.

Lan honetan bio-oilaren (frakzio urtsuaren eta osoaren) erreformatzearen bidezko $\mathrm{H}_{2}$-aren ekoizpena aztertzen da hainbat egileren operazio-estrategiak alderatuz eta lan honen egileek proposatutako estrategiaren emaitzen onurak azpimarratuz. Bestetik, $\mathrm{CO}_{2}$-aren in situ harrapaketaren estrategia sinergikoa erakusten da.

\section{BIO-OILAREN ERREFORMATZE KATALITIKOA}

\subsection{Bio-oilaren frakzio urtsuaren erreformatzea}

Bio-oilaren frakzio urtsua lortzen da fase-bereizketaren bidez, biooil osoari ura gehituz [21]. Lehenengo ikerketak ohantze finkoan egin ziren [22], bio-oilaren ur-kantitate handiak erabiliz $\left(\mathrm{CH}_{2.54} \mathrm{O}_{0.64}\right.$ eta $\mathrm{CH}_{3.24} \mathrm{O}_{0.78}$ formula molekularraz) eta katalizatzaile-desaktibazioa motelduz [23]. Ohantzearen blokeo-arazoak ohantze fluidizatuzko erreaktorea erabiliz moteldu ziren [24] eta teknologia hori orokortu zen [25-27]. Czernik eta lagunek [24] desaktibazioa moteldu zuten gas naturala ko-elikatuz.

Basagianis eta Verykios-ek [28] operazio-arazoak azpimarratu zituzten, hain zuzen, eratorri termikoa duen kokea (lignina pirolisiaren deribatuen polimerizazioa) erreaktorearen hormetan uzteak eragindakoak. Horrek spouted bed erreaktorearen erabilera bultzatu zuen [29].

Lan gehienetan erabilitako katalizatzaileak Ni-ean oinarrituta daude, esate baterako, komertzialak nafta erreformatzearentzat $[22,24,30], \mathrm{Ni} /$ $\mathrm{Al}_{2} \mathrm{O}_{3} \mathrm{Ca}$ edo $\mathrm{Mg}$-ekin aldatuak [26], Ni/dolomita [25], Ni/MgO [27], $\mathrm{MgO}-\mathrm{La}_{2} \mathrm{O}_{3}-\mathrm{Al}_{2} \mathrm{O}_{3}$ euskarriaren gaineko $\mathrm{Co}$-a gehituz $[31,32]$ eta $\mathrm{La}_{2} \mathrm{O}_{3}$ $\mathrm{Al}_{2} \mathrm{O}_{3}$ euskarriaren gaineko Ni-a erabiliz [33]. Halaber, metal nobleak fase aktiboan erantsi diren katalizatzaileak erabili dira, esate baterako monolitoen gainean jasandako $\mathrm{Ru}-\mathrm{Mg}-\mathrm{Al}_{2} \mathrm{O}_{3}$ fasea, zeramikazko material porotsuak eta $\gamma-\mathrm{Al}_{2} \mathrm{O}_{3}[28]$.

Bibliografian agertzen diren emaitza guztiak alderatzea bereziki zaila da askotariko operazio-baldintza, erreaktore mota eta katalizatzaileak erabiltzen 
direlako. Erabili diren operazio-baldintzak hauek dira: erreformatze tenperatura $600{ }^{\circ} \mathrm{C}$ eta $850{ }^{\circ} \mathrm{C}$ artekoa da, $\mathrm{S} / \mathrm{C}$ (lurrun/karbonoa) erlazio molarra 5 eta 15 artekoa eta askotariko abiadura espazialak $\left(\mathrm{G}_{\mathrm{Cl}} \mathrm{HSV}=0.1-12.000 \mathrm{~h}^{-1}\right)$. Nolanahi ere, egile guztiek bat egin dute ohantze fluidizatuen erreaktoreek koke uztearen inguruko arazoak murrizten dituztela. Emaitzei dagokienez, $\mathrm{H}_{2}$-aren etekinean tarte handia dago, \% 43ren eta \% 90ren artean. Azpimarratzekoa da, 2. irudian erakusten den bezala, Remiro eta lagunek [33] emaitza horiek hobetu dituztela bi etapako sistema original bat erabiliz (2. irudia). Lehenengo etapa termikoa da (katalizatzailerik gabea), non lignina pirolitikoa bereizten den era kontrolatu batean, $500{ }^{\circ} \mathrm{C}$-an. Bigarrenean, erreformatze katalitikoa egiten da. Sistema horrekin lortutako emaitzek agerian jarri dute lignina pirolitikoa kentzeko etapa termikoak operazio-baldintzak leundu dituela eta, horrela, erreakzio-indize hobeak lortu dituzte (3. irudia).

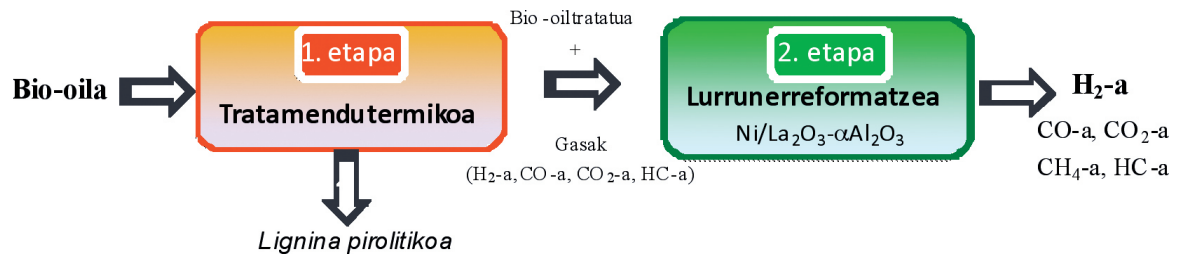

2. irudia. Bi etapako erreakzio-sistema [33].

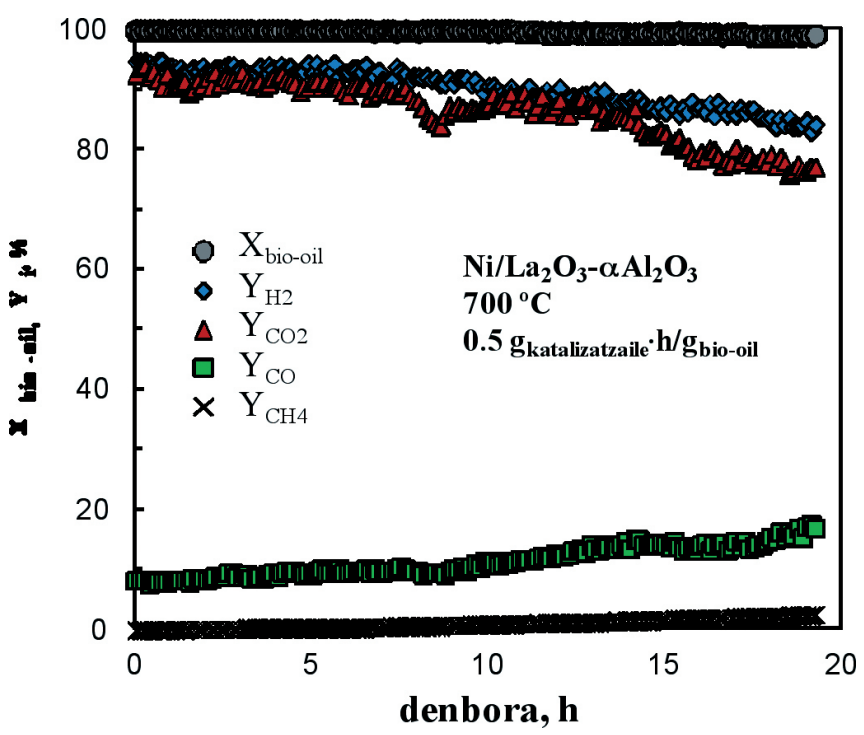

3. irudia. Bio-oilaren ur-frakzioaren lurrun-erreformatzea $700{ }^{\circ} \mathrm{C}$-an Ni/ $\mathrm{La}_{2} \mathrm{O}_{3}-\alpha \mathrm{Al}_{2} \mathrm{O}_{3}$ katalizatzailea erabiliz [33]. 
3. irudian agertzen diren emaitzek adierazten dute $\mathrm{Ni} / \mathrm{La}_{2} \mathrm{O}_{3}-\alpha \mathrm{Al}_{2} \mathrm{O}_{3}$ katalizatzailearen egonkortasuna altua dela, 20 ordutan $\mathrm{H}_{2}$-aren etekinaren jaitsiera txikia baita $\% 95$ tik $\% 84 \mathrm{ra}), 700{ }^{\circ} \mathrm{C}$-an eta $0,5 \mathrm{~g}_{\text {katalizatzaile }} \cdot \mathrm{h} / \mathrm{g}_{\text {bio-oil }}$ denbora espaziala erabiliz.

Azpimarratzekoa da atrizioak eragiten duen material-galera moteldu beharra dagoela (eguneko \% 5, Czernik eta lagunen [24] arabera) katalizatzaile-erabilpenerako ohantze fluidizatuan, eta alderdi hau kontuan hartu behar da katalizatzaileen euskarrien hautaketan.

\subsection{Bio-oil osoaren erreformatzea}

Egile gutxik ikertu dute bio-oil osoaren erreformatzea etapa katalitiko bakar batean, bio-oil osoaren balioztatzearen arazoa dela eta (operatibitate-arazoak eta katalizatzailearen desaktibazio azkarra). Hainbat egileren emaitzen bilduma erakusten da 1. taulan, operazio-baldintzak, katalizatzailea, erreaktore mota eta erreakzio-indize nagusiak aipatuz.

Seyedeyn-Azad eta lagunek [34], ohantze finkoan eta Ni/ $\mathrm{Al}_{2} \mathrm{O}_{3} \mathrm{ka}-$ talizatzailea erabiliz, \% 73 balizko $\mathrm{H}_{2}$-aren etekina (honela definituta: lortutako $\mathrm{mol}_{2}$-aren eta $\mathrm{CO}$-aren molen batura zati estekiometrikoki lor daitezkeen $\mathrm{mol} \mathrm{H}_{2}$-aren molak) lortu zuten, $950{ }^{\circ} \mathrm{C}$-an, $\mathrm{S} / \mathrm{C}=5$ eta WHSV $=13 \mathrm{~h}^{-1}, \mathrm{CH}_{1.87} \mathrm{O}_{0.754}$ batez besteko formulaz (ura barne) bio-oila balioztatuz. Egile horiek frogatu zuten ikertu zituzten katalizatzaileen artean, $\mathrm{Ni} / \mathrm{Zr}_{2} \mathrm{O}_{3}$ katalizatzaileak aktibitaterik altuena lortzen zuela, $\% 79$ balizko $\mathrm{H}_{2}$-aren etekinarekin [35]. Ru-rekin sustatutako $\mathrm{Ni} / \mathrm{Al}_{2} \mathrm{O}_{3}$ katalizatzailearen aktibitate altua ere frogatu zuten, hain zuzen ere, $\% 85$ balizko $\mathrm{H}_{2}$-aren etekina lortuz [36]. Hala eta guztiz ere, katalizatzaile horiekin guztiekin erreaktorean utzitako kokea elikatutako karbonoaren \% 30 da.

Biomasaren ligninaren pirolisitik datozen konposatuen birpolimerizazioaren arazoari aurre egiteko, hainbat estrategia proposatu dira. Guztien artean hauexek gailendu dira:

- Erreformatze-krakeo zikloen operazioa [38,42], bi etapako ziklo sekuentzialez osatua: i) bio-oil erreformatzea $\left(\mathrm{CH}_{1.32} \mathrm{O}_{0.54}\right.$ konposizioaz) $\mathrm{Ce}_{0.5} \mathrm{ZrO}_{0.5} \mathrm{O}_{2}$-ek eutsitako Pt edo $\mathrm{Rh}$ katalizatzaileak erabiliz, zuzenenan erabilia edo kordieritazko monolitoetan sustatua eta ii) katalizatzaile-erregenerazioa koke errekuntzaren bidez. Etapa endotermikoaren (erreformatzearen) eta exotermikoaren (koke errekuntzaren) konbinazioak egoera pseudo-autotermikoa lortzea ahalbidetzen du.

- Metanolaren ko-elikatzea [41]. Bio-oila egonkortzeko beharra dela eta, \% 10 metanola erabiltzen da. Horrela, erreformatzea era zentralizatuan egin daiteke, bio-oila modu ez-zentralizatuan ekoiztu ondoren. Ni katalizatzailearekin (nafta erreformatzearen katalizatzaile komertziala erabiliz) $\% 70 \mathrm{~b} / \mathrm{b} \mathrm{H} \mathrm{H}_{2}$ eta $\% 90 \mathrm{H}_{2}$ etekina lortzen da. 


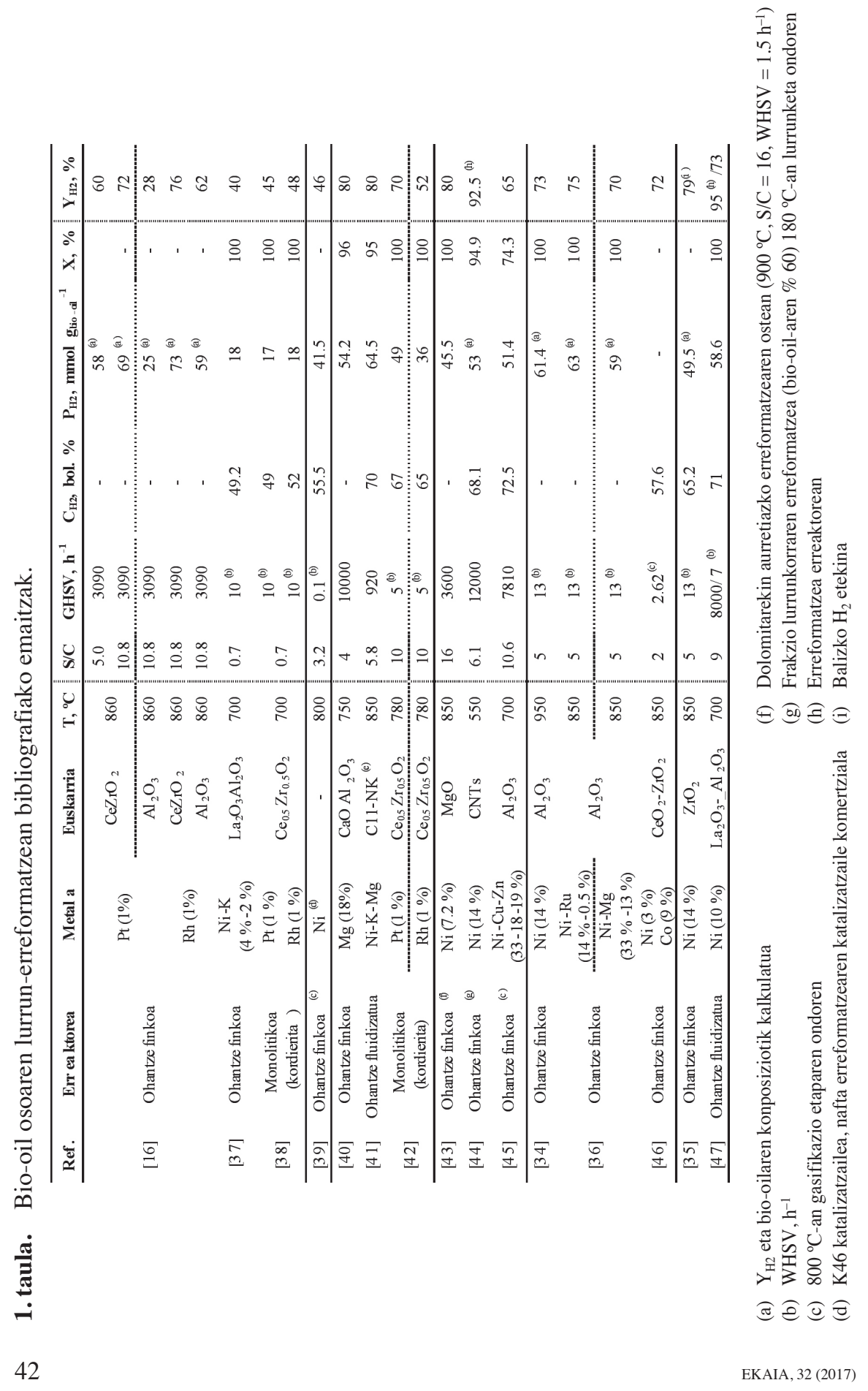


Etekin hori \% 70era jaisten da 10 ordu ondoren, koke-desaktibazioa eta katalizatzaile-atrizioa dela eta.

- Bi etapa katalitikoko erreformatzea seriean [43], bi ohantze finkoekin, lehenengoan dolomita jarriz kokearen uzte nagusia eragiteko eta honen ondoren, $\mathrm{Ni} / \mathrm{MgO}$ katalizatzaile bat. Konbertsio altua lortzeko beharrezkoa da $850{ }^{\circ} \mathrm{C}$-tik gora eta S/C 12-tik gora lan egitea.

- Aurreko lignina pirolitikoaren bereizketa. Wang eta lagunek [40] bio-oil osoa $\left(\mathrm{CH}_{2.33} \mathrm{O}_{0.95} 0.56 \mathrm{H}_{2} \mathrm{O}\right)$ pirolizatzen dute. Horrela, lignininaren pirolisiaren deribatuek lurrungailuan birpolimerizatzen dute eta lurrunkorrak $\left(\mathrm{CH}_{2.70} \mathrm{O}_{0.50} 0.79 \mathrm{H}_{2} \mathrm{O}\right)$ erreformatzen dira ohantze finkozko erreaktore batean, $\mathrm{Mg} / \gamma-\mathrm{Al}_{2} \mathrm{O}_{3}$ eta $\mathrm{C} 12 \mathrm{~A} 7-\mathrm{O} / 18 \% \mathrm{Mg} \mathrm{ka}-$ talizatzaileekin. Egile horiek azpimarratzen dute katalizatzaile horien erregenerazio ahalmena, kokearen gasifikazioaren bidezkoa.

van Rossum eta lagunek [48] bi etapako sistema batekin lan egiten dute lignina pirolitikoa bereizteko: lehena, arezko ohantze fluidizatua, katalizatzailerik gabea, non $500{ }^{\circ} \mathrm{C}$-tik gora lurruntze eta gasifikazio primarioa gertatzen den; bigarrena, lurrunkorrak seriean erreformatzen dira ohantze finkozko erreaktore katalitikoan $700{ }^{\circ} \mathrm{C}$-tik gora (koke uztea murrizteko). Bi erreaktoreen artean, beirazko esferen ohantze bat ezartzen da lignina pirolitikoaren eta tar-en konposatu pisutsuen atxikitzea errazteko.

Remiro eta lagunek [47] frakzio urtsuarekin erabili den moduan (3. irudia) bi etapako sistema erabiltzen dute. 4 . irudian erakusten da sistema ho-

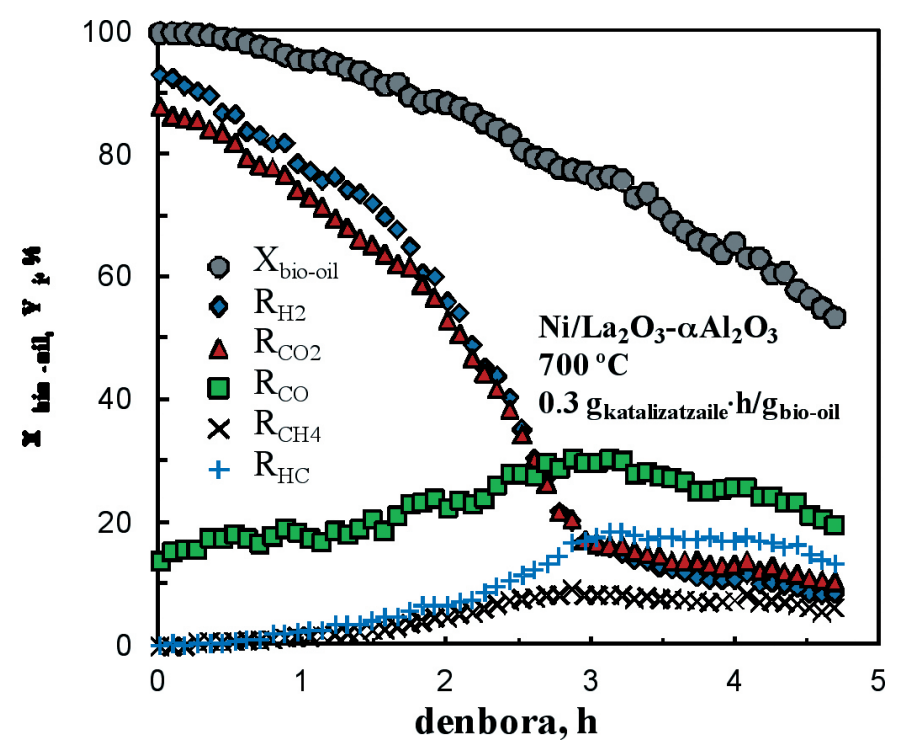

4. irudia. Bio-oil osoaren lurrun erreformatzea $700{ }^{\circ} \mathrm{C}$-an $\mathrm{Ni} / \mathrm{La}_{2} \mathrm{O}_{3}-\alpha \mathrm{Al}_{2} \mathrm{O}_{3}$ katalizatzailea erabiliz. 
rrekin $41.8 \mathrm{mmol} \mathrm{H}_{2} / \mathrm{g}_{\text {bio-oil }}$ lortzen dela $\mathrm{H}_{2}$-aren etekin eta selektibitate altuekin (\% 94 eta \% 71, hurrenez hurren), $700{ }^{\circ} \mathrm{C}$-an (lan gehienak baino $100{ }^{\circ} \mathrm{C}$ gutxiagotan) eta lignina pirolitikoa bezalako azpiproduktua balioztagarria lortuz [49].

\subsection{Bio-oilaren erreformatzea $\mathrm{CO}_{2}$-aren in situ harrapaketarekin}

Zenbait egilek planteatu dute $\mathrm{CO}_{2}$-aren in situ harrapaketa erreformatze-erreaktorean, hidrokarburoentzat eta beste konposatu oxigenatuentzat,
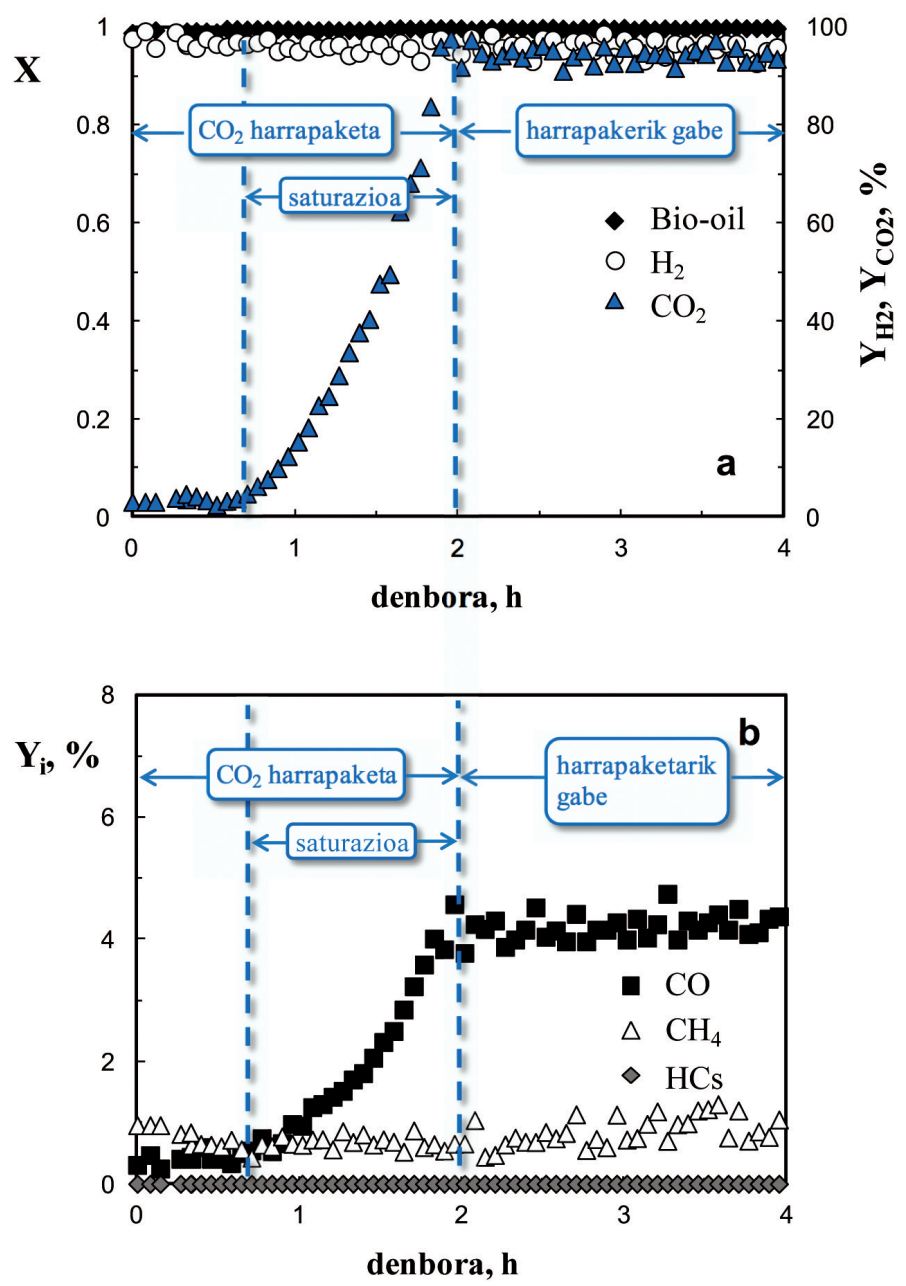

5. irudia. Bio-oilaren lurrun-erreformatzea $\mathrm{CO}_{2}$-aren in situ harrapaketarekin $600{ }^{\circ} \mathrm{C}$-an $\mathrm{Ni} / \mathrm{La}_{2} \mathrm{O}_{3}-\alpha \mathrm{Al}_{2} \mathrm{O}_{3}$ katalizatzailea erabiliz. 
baina oraindik ikerketa gutxi egin dira bio-oila erabiliz [50-52]. $\mathrm{CO}_{2}$-aren harrapaketak hainbat hobekuntza ekar ditzake prozesu orokorrera: i) $\mathrm{H}_{2}$ selektibitatea areagotzen da ia korronte purua lortuz, ii) $\mathrm{H}_{2}$ etekina handitu daiteke WGS (Ek. 2) eta erreformatzearen erreakzioaren (Ek. 1) oreka termodinamikoak desplazatuz, eta iii) erreformatzearen bero beharra orekatzen da karbonatazio-erreakzio exotermikoarekin.

Remiro eta lagunek [50] $\mathrm{CO}_{2}$-aren in situ harrapaketarekin prozesu integratuaren ikerketa egin dute $\mathrm{Ni} / \mathrm{La}_{2} \mathrm{O}_{3}-\alpha \mathrm{Al}_{2} \mathrm{O}_{3}$ katalizatzailea erabiliz eta $\mathrm{CO}_{2}$-a harrapatzeko, dolomita adsorbatzailea gisa erabiliz (5. irudia). Emaitza garrantzitsuak lortu dituzte ia $\% 100$ eko $\mathrm{H}_{2}$ selektibitatera helduz, eta horrela, hurrengo purifikazio-etapa errazten da. Horretaz gain, katalizatzaile/dolomita erlazioaren garrantzia nabarmendu dute, katalizatzailearen eta dolomitaren arteko aldeko sinergia lortzeko. Izan ere, erlazio-balio txikiek $\mathrm{CH}_{4}$-ren ekoizpenari laguntzen diote eta horren ondorioz, $\mathrm{H}_{2}$-ren etekina jaisten da eta katalizatzailearen egonkortasuna murrizten da.

\section{ONDORIOAK}

Bio-oilaren (biomasaren pirolisi azkarraren produktu likidoaren) erreformatzea interes handiko balioztatze-bidea da $\mathrm{H}_{2}$-a lortzeko, batik bat $\mathrm{H}_{2}$ aren eskariaren igoeragatik eta egungo ingurumen-errekerimenduei erantzuten dielako, betiere lehengai eta erregai gisa erabiltzeko.

Prozesu honen arazo garrantzitsuena da lignina prolitikoa katalizatzailean uzten dela, eta horrek desaktitibazio azkarra eragiten duela. Egileek desaktibazioa moteltzea lortu dute, aurretiko etapa baten bidez, zeinek azpiproduktu horren bereizketa eragiten duen.

Bio-oilaren erreformatzean Ni-ean onarritutako katalizatzaileak erabilienak izan dira bibliografian, haien aktibitate, egonkortasun eta kosteagatik. Ohantze fluidizatua erreaktorearen desaktibazioa ekiditeko aproposena dela onartuta dago. Hain zuzen ere, bi etapako sistema batean (termikoa + katalitikoa) eta ohantze fluidizatuan Ni/La $\mathrm{O}_{3}-\alpha \mathrm{Al}_{2} \mathrm{O}_{3}$ katalizatzailea erabiliz, \% 95eko $\mathrm{H}_{2}$ etekina lortu da, bai frakzio urtsuarekin, bai osoarekin. Hala ere, katalizatzaileak egonkortasun handiagoa erakutsi du frakzio urtsua erabilita, 20 orduan aktibitate jaitsiera txikia jasanez.

Bestetik, bio-oilaren erreformatzean egindako $\mathrm{CO}_{2}$-aren in situ harrapaketak agerian jarri du ahalmen handiko alternatiba dela purutasun handiko produktu-korrontea lortzeko, \% $99 \mathrm{H}_{2}$ selektibitatea lortuz $600{ }^{\circ} \mathrm{C}$-an eta CO selektibitate oso txikiekin $(<0.1 \%)$. 


\section{ESKER ONAK}

Artikulu honek Eusko Jaurlaritzaren (IT748-13), Euskal Herriko Unibertsitatearen (UFI 11/39), Espainiako Zientzia eta Berrikuntza Ministerioaren (CTQ2015-68883-R) eta Europa Batasunaren (Horizon 2020, Marie Sklodowska-Curie Grant agreement 704473) diru-laguntzak jaso ditu.

\section{BIBLIOGRAFIA}

[1] DA SILVA, A.; DE SOUZA, K.; JACOBS, G.; GRAHAM, U.; DAVIS, B.; MATTOS, L. eta NORONHA, F. 2011. «Steam and $\mathrm{CO}_{2}$ reforming of ethanol over $\mathrm{Rh} / \mathrm{CeO}_{2}$ catalyst». Applied Catalysis B: Environmental, 102, 94109.

[2] PELAEZ, M.; RIVEROS, G.; TORRES, S.; GARCIA, T. eta ALBORNOZ, E. 2014. «Production and use of electrolytic hydrogen in Ecuador towards a low carbon economy». Energy, 64, 626-631.

[3] NGOH, S.K. eta NJOMO, D. 2012. «An overview of hydrogen gas production from solar energy». Renewable and Sustainable Energy Reviews, 16 (9), 6782-6792.

[4] TRANE, R.; DAHL, S.; SKJØTH-RASMUSSEN, M. eta JENSEN, A. 2012. «Catalytic steam reforming of bio-oil». International Journal of Hydrogen Energy, 37, 6447-6472.

[5] NAHAR, G. eta DUPONT, V. 2012. «Hydrogen via steam reforming of liquid biofeedstock». Biofuels, 3, 167-191.

[6] HAMELINCK, C.N.; SUURS, R.A.A. eta FAAIJ, A.P.C. 2005. «International bioenergy transport costs and energy balance». Biomass and Bioenergy, 29(2), 114-134.

[7] MONTERO, C.; OAR-ARTETA, L.; REMIRO, A. eta GAYUBO, A.G. 2015. « Catalizadores para la obtención de hidrógeno mediante reformado con vapor de compuestos oxigenados derivados de biomasa». Procesos y Energia, 1 (2), 13-33.

[8] BUTLER, E.; DEVLIN, G.; MEIER, D, ETA MCDONNELL, K. 2011. «A review of recent laboratory research and commercial developments in fast pyrolysis and upgrading». Renewable and Sustainable Energy Review, 15, 4171-4186.

[9] MAKIBAR, J.; FERNANDEZ-AKARREGI, R.; ALTZIBAR, H. eta OLAZAR, M. 2012. «Biomasa hondakinak balioztatzeko prozesu motak». Ekaia, 25, 131-141.

[10] GAYUBO, A.G.; VALLE, B.; AGUAYO, A.T.; OLAZAR, M. eta BILBAO, J. 2010. «Pyrolytic lignin removal for the valorisation of biomass pyrolysis crude bio-oil by catalytic transformation». Journal of Chemical Technology \& Biotechnology, 85, 132-144. 
[11] MONTERO, C.; OAR-ARTETA, L.; REMIRO, A.: ARANDIA, A.; BILBAO, J. ETA GAYUBO, A.G. 2015. " Thermodynamic comparison between bio-oil and ethanol steam reforming». International Journal of Hydrogen Energy, 40, 15963-15971.

[12] RABENSTEIN, G. eta HACKER, V. 2008. «Hydrogen for fuel cells from ethanol by steam-reforming, partial-oxidation and combined auto-thermal reforming: A thermodynamic analysis». Journal of Power Sources, 185 (2), 1293-1304.

[13] BASAGIANIS, A. eta VERYKIOS, X. 2006. «Reforming reactions of acetic acid on nickel catalysts over a wide temperature range». Applied Catalysis A: General, 308, 182-193.

[14] BIMBELA, F.; OLIVA, M.; RUIZ, J.; GARCÍA, L. eta ARAUZO, J. 2007. «Hydrogen production by catalytic steam reforming of acetic acid, a model compound of biomass pyrolysis liquids». Journal of Analytical and Applied Pyrolysis, 79, 112-120.

[15] MEDRANO, J.A.; OLIVA, M.; RUIZ, J.; GARCIA, L. eta ARAUZO, J. 2009. «Catalytic steam reforming of model compounds of biomass pyrolysis liquids in fluidized bed reactor with modified $\mathrm{Ni} / \mathrm{Al}$ catalysts». Journal of Analytical and Applied Pyrolysis, 85 (1-2), 214-225.

[16] RIOCHE, C.; KULKARNI, S.; MEUNIER, F.; BREEN, J. eta BURCH, R. 2005. «Steam reforming of model compounds and fast pyrolysis bio-oil on supported noble metal catalysts». Applied Catalysis B: Environmental, 61, 130-139.

[17] RAMOS, M.; NAVASCUÉS, A.I.; GARCÍA, L. eta BILBAO, R. 2007. «Hydrogen production by catalytic steam reforming of acetol, a model compound of bio-oil». Industrial \& Engineering Chemistry Research, 46, 23992406.

[18] BONA, S.; GUILLÉN, P.; ALCALDE, J.G.; GARCÍA, L. eta BILBAO, R. 2008. «Toluene steam reforming using coprecipited $\mathrm{Ni} / \mathrm{Al}$ catalysts modified with lanthanum or cobalt». Chemical Engineering Journal, 137, 587-597.

[19] ZHAO, B.; ZHANG, X.; CHEN, L.; QU, R.; MENG, G.; YI, X. eta SUN, L. 2010. «Steam reforming of toluene as model compound of biomass pyrolysis tar for hydrogen». Biomass and Bioenergy, 34, 140-144.

[20] MARQUEVICH, M.; CZERNIK, S.; CHORNET, E. eta MONTANE, D. 1999. «Hydrogen from Biomass: Steam Reforming of Model Compounds of Fast-Pyrolysis Oil». Energy \& Fuels, 13, 1160-1166.

[21] VALLE, B.; REMIRO, A.; AGUAYO, A.T.; BILBAO, J. eta GAYUBO, A.G. 2013. «Catalysts of $\mathrm{Ni} / \alpha-\mathrm{Al}_{2} \mathrm{O}_{3}$ and $\mathrm{Ni} / \mathrm{La}_{2} \mathrm{O}_{3}-\alpha \mathrm{Al}_{2} \mathrm{O}_{3}$ for hydrogen production by steam reforming of bio-oil aqueous fraction with pyrolytic lignin retention». International Journal of Hydrogen Energy, 38, 13071318 .

[22] WANG, D.; CZERNIK, S. eta CHORNET, E. 1998. «Production of hydrogen from biomass by catalytic steam reforming of fast pyrolysis oils». Energy \& Fuels, 12, 19-24. 
[23] CHEN, T.; WU, C. eta LIU, R. 2011. «Steam reforming of bio-oil from rice husks fast pyrolysis for hydrogen production». Bioresource Technology, 102, 9236-9240.

[24] CZERNIK, S.; FRENCH, R.; FEIK, C. eta CHORNET, E. 2002. «Hydrogen by catalytic steam reforming of liquid byproducts from biomass thermoconversion processes». Industrial \& Engineering Chemistry Research, 41, 42094215.

[25] LI, H.; XU, Q.; XUE, H. eta YAN,Y. 2009. «Catalytic reforming of the aqueous phase derived from fast-pyrolysis of biomass». Renewable Energy, 34, 2872-2877.

[26] MEDRANO, J.; OLIVA, M.; RUIZ, J.; GARCÍA, L. eta ARAUZO, J. 2011. «Hydrogen from aqueous fraction of biomass pyrolysis liquids by catalytic steam reforming in fluidized bed». Energy, 36, 2215-2224.

[27] ZHANG, S.; LI, X.; XU, Q. eta YAN, Y. 2011. «Hydrogen production from the aqueous phase derived from fast pyrolysis of biomass». Journal of Analytical and Applied Pyrolysis, 92, 158-163.

[28] BASAGIANIS, A. eta VERYKIOS, X. 2007. «Steam reforming of the aqueous fraction of bio-oil over structured $\mathrm{Ru} / \mathrm{MgO} / \mathrm{Al}_{2} \mathrm{O}_{3}$ catalysts». Catalysis Today, 127, 256-264.

[29] KECHAGIOPOULOS, P.; VOUTETAKIS, S.; LEMONIDOU, A. eta VASALOS, I. 2009. «Hydrogen production via reforming of the aqueous phase of bio-oil over Ni/olivine catalysts in a spouted bed reactor». Industrial \& Engineering Chemistry Research, 48, 1400-1408.

[30] PAASIKALliO, V.; AZHARI, A.; KIHLMAN, J.; SIMELL, P. eta LEHTONEN, J. 2015. «Oxidative steam reforming of pyrolysis oil aqueous fraction with zirconia pre-conversion catalyst». Int. J. Hydrogen Energy, 40, 12088-12096.

[31] GARCIA, L.; FRENCH, R.; CZERNIK, S. eta CHORNET, E. 2000. «Catalytic steam reforming of bio-oils for the production of hydrogen: effects of catalyst composition». Applied Catalysis A: General, 201 (2), 225-239.

[32] REMÓN, J.; MEDRANO, J.A.; BIMBELA, F.; GARCÍA, L. eta ARAUZO, J. 2013. «Ni/Al-Mg-O solids modified with $\mathrm{Co}$ or $\mathrm{Cu}$ for the catalytic steam reforming of bio-oil». Applied Catalysis B: Environmental, 132-133, 433444.

[33] REMIRO, A.; VALle, B.; AGUAYO, A.T.; BILBAO, J. eta GAYUBO, A.G. 2013. «Operating conditions for attenuating $\mathrm{Ni} / \mathrm{La}_{2} \mathrm{O}_{3}-\alpha \mathrm{Al}_{2} \mathrm{O}_{3}$ catalyst deactivation in the steam reforming of bio-oil aqueous fraction». Fuel Processing Technology, 115, 222-232.

[34] SEYEDEYN-AZAD, F.; SALEHI, E.; ABEDI, J. eta HARDING, T. 2011. «Biomass to hydrogen via catalytic steam reforming of bio-oil over Ni-supported alumina catalysts». Fuel Processing Technology, 92, 563-569.

[35] SEYEDEYN-AZAD, F.; ABEDI, J. eta HARDING, T. 2012. «Production of hydrogen via steam reforming of bio-oil over Ni-based catalysts: Effect of support». Chemical Engineering Journal, 180, 145-150. 
[36] SALEHI, E.; SEYEDEYN-AZAD, F.; HARDING, T. eta ABEDI, J. 2011. «Production of hydrogen by steam reforming of bio-oil over $\mathrm{Ni} / \mathrm{Al}_{2} \mathrm{O}_{3}$ catalysts: Effect of addition of promoter and preparation procedure». Fuel Processing Technology, 92, 2203-2210.

[37] DAVIDIAN, T.; GUILHAUME, N.; IOJOIU, E.; PROVENDIER, H. eta MIRODATOS, C. 2007. «Hydrogen production from crude pyrolysis oil by a sequential catalytic process». Appl. Catal. B: Environmental, 73, 116-127.

[38] IOJOIU, E.E.; DOMINE, M.E.; DAVIDIAN, T.; GUILHAUME, N. eta MIRODATOS, C. 2007. «Hydrogen production by sequential cracking of biomass-derived pyrolysis oil over noble metal catalysts supported on ceria-zirconia». Applied Catalysis A: General, 323, 147-161.

[39] VAN ROSSUM, G.; KERSTEN, S.R.A. eta VAN SWAAIJ, W.P.M. 2007. «Catalytic and noncatalytic gasification of pyrolysis oil». Industrial \& Engineering Chemistry Research, 46, 3959-3967.

[40] WANG, Z.; PAN, Y.; DONG, T.; ZHU, X.; KAN, T.; YUAN, L.; TORIMOTO, Y.; SADAKATA, M. eta LI, Q. 2007. «Production of hydrogen from catalytic steam reforming of bio-oil using C12A7-O-based catalysts». Applied Catalysis A: General, 320, 24-34.

[41] CZERNIK, S.; EVANS, R. eta FRENCH, R. 2007. «Hydrogen from biomass production by steam reforming of biomass pyrolysis oil». Catalysis Today, 129, 265-268.

[42] DOMINE, M.E.; IOJOIU, E.E.; DA VIDIAN, T.; GUILHAUME, N. eta MIRODATOS, C. 2008. «Hydrogen production from biomass-derived oil over monolithic Pt- and Rh-based catalysts using steam reforming and sequential cracking process». Catalysis Today, 133-135, 565-573.

[43] WU, C.; HUANG, Q.; SUI, M.; YAN, Y. eta WANG, F. 2008. «Hydrogen production via catalytic steam reforming of fast pyrolysis bio-oil in a twostage fixed bed reactor system». Fuel Processing Technology, 89, 13061316.

[44] HOU, T.; YUAN, L.; YE, T.; GONG, L.; TU, J.; YAMAMOTO, M.; TIRIMOTO, Y. eta LI, Q. 2009. «Hydrogen production by low-temperature reforming of organic compounds in bio-oil over a CNT-promoting Ni catalyst». International Journal of Hydrogen Energy, 2009, 34, 9095-9107.

[45] KAN, T.; XIONG, J.; LI, X.; YE, T.; YUAN, L.; TORIMOTO, Y.; YAMAMOTO, M. eta LI, Q. 2010. « High efficient production of hydrogen from crude bio-oil via an integrative process between gasification and current-enhanced catalytic steam reforming». International Journal of Hydrogen Energy, 35, 518-532.

[46] ZHANG, Y.; LI, W.; LI, Q.; XU, Q. eta YAN, Y. 2012. «Steam reforming of bio-oil for hydrogen production: effect of Ni-Co bimetallic catalysts». Chemical Engineering \& Technology, 35, 302-308.

[47] REMIRO, A.; VALlE, B.; AGUAYO, A. T.; BILBAO, J. eta GAYUBO, A.G. 2013. «Steam reforming of raw bio-oil in a fluidized bed reactor with prior separation of pyrolytic lignin». Energy \& Fuels, 27, 7549-7559. 
[48] VAN ROSSUM, G.; KERSTEN, S. eta VAN SWAAIJ, W. 2009. «Staged catalytic gasification/steam reforming of pyrolysis oil». Industrial \& Engineering Chemistry Research, 48, 5857-5866.

[49] OCHOA, A.; ARAMBURU, B.; IBAÑEZ, M.; VALLE, B.; BILBAO, J.; GAYUBO, A.G. eta CASTAÑO, P. 2014. «Compositional insights and valorisation pathways for the carbonaceous material deposited during bio-oil thermal treatment». ChemSusChem, 7, 2597-2608.

[50] REMIRO, A.; VALlE, B.; ARAMBURU, B.; AGUAYO, A.T.; BILBAO, J. eta GAYUBO, A.G. 2013. «Steam reforming of the bio-oil aqueous fraction in a fluidized bed reactor with in-situ $\mathrm{CO}_{2}$ capture». Industrial \& Engineering Chemistry Research, 52, 17087-17098.

[51] XIE, H.; YU, Q.; ZUO, Z.; HAN, Z.; YAO, X. eta QIN, Q. 2016. «Hydrogen production via sorption-enhanced catalytic steam reforming of bio-oil». International Journal of Hydrogen Energy, 41, 2345-2353.

YAN, C.F.; HU, E.Y. eta CAI, C.L. 2010. «Hydrogen production from bio-oil aqueous fraction with in situ carbon dioxide capture». International Journal of Hydrogen Energy, 35, 2612-2016. 